\title{
Ecologia, Filosofia e Conservação
}

\author{
Félix Baumgarten Rosumek ${ }^{1}$ \& Rogério Parentoni Martins ${ }^{2, *}$
}

\author{
${ }^{1}$ Centro de Ciências Biológicas, Universidade Federal de Santa Catarina - UFSC, Florianópolis, SC, Brasil \\ ${ }^{2}$ Departamento de Biologia, Universidade Federal do Ceará - UFC, Fortaleza, CE, Brasil
}

\begin{abstract}
"Ecologia" e "conservação" escaparam do vocabulário acadêmico para atualmente integrar o discurso ambiental da mídia, governos e ONGs. A maioria dos cidadãos minimamente informados tem noção destes conceitos e outros, como "preservação", "recursos naturais", "mudanças climáticas" e "sustentabilidade". Esse público sabe também que tais conceitos estão, de algum modo, inter-relacionados, embora estas conexões sejam muitas vezes obscuras.
\end{abstract}

Um termo que não tem uma conexão tão imediata com conservação é "filosofia". Afinal, os ambientalistas são vistos como pessoas ativas: estão em campo, salvam indivíduos de espécies ameaçadas, discutem suas demandas políticas e sociais (vez por outra abraçam uma árvore ou abordam um navio baleeiro). Por sua vez, o filósofo é considerado um ser estranho, desvinculado da realidade, perdido em argumentações intermináveis e distantes das necessidades práticas.

Este enquadramento estereotipado reflete a fragmentação do conhecimento acadêmico, em que cada área é vista como distinta e precisamente definida em função de seus objetos de estudo e métodos. Há sentido lógico na divisão do conhecimento por disciplinas, da mesma forma que em qualquer conceituação: nomear determinados conjuntos de coisas é fundamental à comunicação, seria inviável cada um atribuir a um objeto ou fenômeno uma palavra à sua escolha Deste modo, sabemos em que periódicos procurar informações acadêmicas sobre política e sistemas sociais, e não vamos a um departamento de física para perguntar sobre as últimas novidades sobre a sistemática de coleópteros.

Tão acostumados estamos a estas subdivisões que as assumimos como fronteiras rígidas e nos esquecemos que são de conveniência. O número de grupos interdisciplinares em universidades é ainda limitado comparado a pesquisadores entrincheirados em seus departamentos ou núcleos de pesquisa. Tal fragmentação atinge níveis extremos: o

\footnotetext{
*Send correspondence to: Rogério Parentoni Martins

Departamento de Biologia, Universidade Federal do Ceará - UFC,

Fortaleza, CE, Brasil

E-mail: wasp@icb.ufmg.br
}

Conselho Nacional de Pesquisa (CNPq) reconhece cerca de 1.300 áreas de conhecimento. Há necessidade de síntese e integração de conhecimentos, especialmente porque há inúmeras conexões entre disciplinas.

Mesmo a Biologia da Conservação sendo considerada interdisciplinar, e mais ainda as Ciências Ambientais, é necessário aproximá-las de disciplinas com as quais têm relação menos óbvia. Nesta coluna pretendemos, por meio de dois exemplos, mostrar porque a conservação não pode ser realizada isoladamente, pois depende de doses significativas de conhecimentos científicos (particularmente os ecológicos) e filosóficos para atingir plenamente seus objetivos. Ademais, ao contrário do que possa parecer, a teoria ecológica e a filosofia têm um papel chave na elaboração de respostas consistentes a questões práticas.

\section{A Ecologia na Conservação}

A ecologia dedica-se a estudar as interações entre os seres vivos e destes com o seu meio. Diversas definições já foram propostas, mas o termo sempre se referiu a uma determinada disciplina científica com foco nas relações entre organismos e ambiente. O ambientalismo moderno, por outro lado, é um movimento social com raízes antigas, mas que tomou forma consistente na metade do século XX (Pepper 1996). A idéia central da ideologia ambientalista é a redução dos impactos das atividades humanas sobre os ecossistemas, deste modo conservando o planeta em um determinado estado (considerado "de equilíbrio"). Considerando-se estes objetivos, desde cedo ficou evidente a contribuição potencial da ecologia para solucionar a crise ambiental. Vários ecólogos justificam suas atividades por meio de motivações ambientalistas (e.g., conservação de espécies, recursos ou ecossistemas), e muitos ambientalistas buscam soluções científicas para resolver suas demandas. A relação entre ambas se tornou tão próxima a ponto de, no discurso popular, "ecologia" ser considerada (erroneamente) sinônimo de "ambientalismo". Mas conservar envolve atividades de um conjunto mais amplo de profissionais, desde ecólogos acadêmicos e aplicados, a consultores, ONGs, órgãos públicos e tomadores de decisão.

Mesmo com esta relação estreita, diversas pessoas manifestam certa insatisfação com a ecologia, notadamente as mais 
envolvidas na parte prática da conservação. Por que os ecólogos frequentemente parecem incapazes de fornecer respostas simples e objetivas a questões ambientalistas? Por que, se perguntam a um ecólogo como se deve desenhar uma unidade de conservação, um diz para escolher um grande fragmento único e outro diz para escolher uma série de fragmentos menores? Por que um ecólogo diz que predadores podem aumentar a biodiversidade em um ecossistema e outro diz que podem diminuir? Afinal, há padrões consistentes em ecologia, dos quais podem ser extraídas diretrizes seguras que garantam a eficácia de projetos conservacionistas, sem a necessidade de um longo, detalhado e caro estudo para cada caso?

Este é um verdadeiro "calcanhar de Aquiles ecológico", a dificuldade em dar respostas baseadas em generalizações teóricas. Um marco nessa polêmica foi o livro de Peters (1991), cuja idéia central é a de que o problema reside na própria inconsistência teórica da disciplina: teorias mal-estruturadas, conceitos ambíguos e falta de padronização. Exemplos são variações para conceitos-chave, tal como as 163 definições para "estabilidade" (Grimm \& Wissel 1997). Outros autores declaram que a causa reside no próprio objeto de estudo da ecologia. Os sistemas ecológicos são tão complexos e contingenciais que "leis" seriam impossíveis ou apenas aplicáveis a domínios restritos. É possível que as duas causas estejam interligadas e contribuam para o problema.

A moral da história é que, confrontado com esta situação, nenhum profissional que dependa da ecologia pode se furtar a conhecer a parte teórica, para ser capaz de localizar incoerências e distinguir se determinadas generalizações são aplicáveis em casos particulares. Uma análise da estrutura de teorias é de grande valia para tanto. Pickett et al. (1997) apresentam um ponto de partida através do qual pesquisadores podem identificar os elementos da teoria, como pressupostos, definições e hipóteses, mesmo quando estes não estão explícitos nos trabalhos originais. Esta análise também ajuda a diferenciar conceitos utilizados de modo confuso até na literatura de ponta, como teoria, hipótese e modelo. Esta "consciência teórica" dos profissionais é o primeiro passo para amenizar o imbróglio conceitual apontado por Peters (1991).

Infelizmente, muitos ignoram o desenvolvimento da teoria e tomam suas decisões comodamente a partir de dogmas, aplicando-os a quaisquer situações. Por exemplo, ao declarar que fragmentos florestais maiores sempre serão mais ricos em espécies que os menores, evocando a Teoria de Biogeografia de Ilhas, mas desconsiderando que há uma série de pressupostos para se chegar a esta conclusão. Sem que seja feita a ligação entre prática conservacionista / teoria ecológica / análise filosófica, as respostas continuarão sendo ambíguas e resultados inesperados seguirão aparecendo. Em muitas ocasiões será melhor proteger um fragmento maior do que uma série de pequenos fragmentos. Mas, dependendo da heterogeneidade espacial do ecossistema, do tipo de matriz e de outros fatores, isso pode não funcionar.

\section{Conservar Por Quê?}

Mesmo se nas sociedades humanas fosse levada mais a sério a preocupação com o ambiente, seria difícil para qualquer ambientalista conceber que tudo possa ser conservado. $\mathrm{O}$ tempo e o dinheiro destinados à conservação sempre serão inferiores ao necessário. Ademais, a demanda pelo uso de recursos naturais sempre existirá, pelo menos enquanto houver no mundo um ser humano com o estômago roncando.

Caso se assuma um holismo superficial, pelo qual se confunda que todos os componentes de um sistema têm alguma relevância, com todos os componentes são imprescindíveis, a idéia de conservar perde significado, pois nenhuma ação pode ser tomada simplesmente pela completa ausência de critérios de decisão. Efetivamente, é pouco provável que tudo tenha que ser conservado. Mesmo quando se considera um sistema complexo (como um ecossistema), não se espera que todos os componentes contribuam da mesma forma e intensidade para a manutenção de sua estrutura e processos. Para estabelecer critérios, é preciso de uma escala de mensuração. E só é possível obter tal escala respondendo-se à pergunta: conservar por quê?

Esta é a pergunta principal a ser feita antes da realização de qualquer trabalho conservacionista, até mesmo antes de se pensar em conservação. Mas é surpreendente como a questão é tratada de modo superficial, nos meios acadêmico, social e político (Rosumek 2009). O próprio discurso ambientalista transmite um tom de urgência: já destruímos demais e não há tempo a perder com minúcias teóricas, a conservação é prioridade. A impressão que se tem é de que, não importam as justificativas, a conclusão será a mesma: conservar é importante. Entretanto, mesmo que assim o fosse, toda atitude conservacionista será igual? Qualquer argumento levará à mesma prática? Difícil acreditar.

A ciência apenas não consegue responder essa pergunta. Pensemos, por exemplo, na conservação das espécies. Dentre as justificativas mais evocadas para justificar a conservação de uma espécie em particular, temos três bem representativas: o benefício da conservação para o humano; a existência de valor intrínseco para a espécie; e sua importância para a manutenção da estrutura e processos do ecossistema.

No primeiro caso, temos um argumento utilitário. Supondo que seja realmente vantajoso conservar a espécie, faz sentido que os humanos atuem para manter algo que os beneficia. um fim último, ou seja, mostra porque os humanos devem agir para garantir a conservação da espécie. Além disso, pode ser objetivamente demonstrado, pois é vantajoso para qualquer ser vivo que o ambiente tenha condições propícias para a realização do seu ciclo de vida. Saliente-se que tais benefícios nem sempre serão diretos e imediatos, o que constitui um obstáculo para comprovar a veracidade da declaração, mas não altera a lógica do argumento. Da mesma forma, conclui-se que aquilo que não gera benefício tem pouco interesse conservacionista (como o vírus da varíola - ou, quem sabe, o urso panda). 
No segundo caso, é preciso responder às mesmas perguntas: quais as forças ou fenômenos no universo são responsáveis pelo valor intrínseco, e por que sua existência implica em uma mudança de atitude para com a espécie? O valor intrínseco deverá ser de natureza objetiva, o mais independente possível de interpretações particulares, caso contrário resultará em uma argumentação altamente subjetiva, dependente da vontade pessoal. Seria o mesmo que dizer "a espécie deve ser preservada porque quero". Declaração sem maior peso do que "a espécie NÃO deve ser preservada porque NÃO quero". Sem objetividade (e as argumentações baseadas no valor intrínseco falham neste quesito) o argumento perde força e sua utilidade é colocada em xeque.

O terceiro argumento é mais prontamente considerado "científico". Está embasado no conhecimento ecológico e possui objetividade, pois é possível determinar objetivamente a importância da espécie para o funcionamento do ecossistema. Mas é um argumento que permite a réplica: "e daí?". Por que manter a estrutura e o funcionamento do ecossistema? Por si só o argumento justifica a ação humana? Não, ele não constitui um fim último, portanto é incompleto. Nesta categoria estão diversos outros argumentos encontrados na literatura científica, tal como afirmar que a biodiversidade é importante para a manutenção dos processos evolutivos, ou que populações mínimas viáveis são necessárias para resguardar uma espécie de problemas genéticos. São? E daí?

Isolando-se os argumentos "filosóficos" dos "científicos", sem discuti-los de modo integrado, inicia-se a fragmentação do conhecimento. Assim, justificativas parciais são tomadas como fins últimos, e os conflitos entre os argumentos ficam obscuros. Os argumentos científicos para a conservação são compatíveis com os filosóficos? As ações práticas serão as mesmas para um ecossistema que deve ser protegido porque é útil ao humano ou por ter valor em si mesmo? Deve-se construir pontes entre estas duas partes: para isso a objetividade é uma ferramenta fundamental, já que é compartilhada pela ciência e filosofia.

O ritmo de produção de conhecimento atual é tão acelerado que é impossível existir “especialistas em tudo”. Mas não é necessário embarcar nos detalhes mais profundos de cada disciplina para construírem-se conexões. Lado a lado com a profundidade da especialização, um conhecimento básico, mas amplo, é requisito para tanto, da mesma forma que o diálogo entre as partes. O profissional da conservação deve conhecer a ciência, o cientista deve saber dialogar com os ambientalistas, e ambos não devem ignorar o estranho filósofo. Este é o caminho mais eficiente para o sucesso de qualquer atividade coletiva, seja ecologia, filosofia ou conservação.

\section{Referências}

Pepper D, 1996. Modern Environmentalism: an introduction. London: Routledge.

Peters RH, 1991. A critique for ecology. Cambridge: Cambridge University Press.

Grimm V \& Wissel C, 1997. Babel, or the ecological stability discussions: an inventory and analysis of terminology and a guide for avoiding confusion. Oecologia, 109:323-334.

Pickett STA, Kolasa J \& Jones CG, 2007. Ecological understanding: The nature of the theory and the theory of nature. San Diego: Academic Press.

Rosumek FB, 2009. Conservar por quê? As motivações e objetivos da ideologia ambientalista. [Dissertation]. Belo Horizonte: Universidade Federal de Minas Gerais.

Recebido: Fevereiro 2010 Primeira Decisão: Fevereiro 2010 Aceito: Fevereiro 2010 